\title{
Factors Affecting the Level of Bank Competition: Empirical Evidence in Vietnamese Commercial Banks
}

\author{
Submitted 11/08/19, $1^{\text {st }}$ revision 10/09/19, $2^{\text {nd }}$ revision 23/10/19, Accepted 18/11/19
}

\author{
Le Dinh Hac ${ }^{1}$, Hoang Nguyen Khai ${ }^{2}$, Le Hoang $\mathrm{Anh}^{3}$
}

\begin{abstract}
:
Purpose: There is increasing interest in the trends and requirements associated with improvement in the competition of commercial banks. Many studies have been conducted on this topic in Vietnam as well as in the rest of the world. In the present study, the factors affecting the level of competition in the banking system in Vietnam have been studied.

Design/Methodology/Approach: We employ the Bayesian Multilevel Generalized Linear Model to identify the factors affecting the level of competition in the banking system in Vietnam.

Findings: The findings show that the eight variables that affect the level of competition in Vietnam commercial banks were identified, including previous-year competition, equity on total assets ratio, loans on total assets ratio, operating expense on the operating income ratio, return on equity, bank size, economic growth, and inflation rate. Moreover, the results demonstrated that during the 2008-2009 crisis, there was a positive relationship between the crisis and the Lerner index.

Practical Implications: Based on the research results, we provide policy implications to improve the competitive status of commercial banks in Vietnam.

Originality/Value: The results of the present study would serve as a basis for assisting the policy-makers and the other stakeholders to better understand the current state of bank competition and the factors affecting the level of bank competition, which would assist them in formulating strategies and solutions to improve bank competition in Vietnam.
\end{abstract}

Keywords: Competition; Bayesian Multilevel Generalized Linear Model; Commercial banks.

JEL Codes: G21, G32, R15.

Article Type: Research paper.

\footnotetext{
${ }^{1}$ Faculty of Postgraduate Education, Banking University HCMC, 56 Hoang Dieu, Thu Duc District, Ho Chi Minh City, Vietnam, E-mail: hacld@buh.edu.vn

${ }^{2}$ Faculty of Business Administration, Ho Chi Minh City of Technology, 475A Dien Bien Phu Street, Binh Thanh District, Ho Chi Minh City, Vietnam, E-mail: hn.khai@hutech.edu.vn ${ }^{3}$ Institute for Research Science and Banking Technology, Banking University HCMC, 56 Hoang Dieu, Thu Duc District, Ho Chi Minh City, Vietnam, E-mail: anhlh_vnc@buh.edu.vn
} 


\section{Introduction}

In the period between 2011 and 2016, Vietnam's banking and finance sector witnessed several mergers, acquisitions, and restructuring of the commercial banks under the project named "Restructuring Credit Institutions (CIs) for the period 20112015" which was approved by the then Prime Minister of the nation. One of the main objectives of this project was to improve the domestic and international competition of Vietnamese commercial banks, prioritize the handling of weak CIs, conducting mergers, consolidation, and acquisitions of CIs on the basis of the principle of voluntariness; increase chartered capital and handle the bad debts of CIs, and gradually restructure the CIs' operation, management, and administration.

This project commenced by the Government resulted in the reduction in the number of banks in the system as the weak banks were obligated to merge. The mergers and acquisitions of the Vietnamese commercial banks also raised concerns regarding the possibility of a decline in the competition in the banking industry and the resultant impact on the financial stability of the Vietnamese commercial banks.

The trend to improve the competition between commercial banks is increasing. A number of studies have been conducted on this topic in Vietnam as well as in the rest of the world. However, the previous studies conducted so far have not assessed the level of competition and the factors affecting the competition in different conditions such as normal conditions and economic crisis. In addition, the majority of the previous studies conducted in this area have assessed only the intrinsic factors of the bank. The external factors with the degree of competition in the Vietnamese banking system have not yet been explored.

Therefore, the present study was required to supplement the empirical evidence for the level of competition and the factors affecting the level of competition in the banking system in the developing countries in general and in Vietnam in particular. The results of the present study would serve as a basis for assisting the policymakers and the other stakeholders to better understand the current state of bank competition and the factors affecting the level of bank competition, which would assist them in formulating strategies and solutions to improve bank competition in Vietnam.

\section{Literature Review}

Competition has been there since the existence of a commodity economy, and over time, competition has been accompanied by the development of commodity economy. Several economists have conducted studies regarding competition, and several concepts of competition have been developed.

According to Samuelson and Nordhaus (1985), competition is the rivalry between the competing businesses to win the customers or markets. 
According to Porter (1985), competitive advantage is first of all based on the ability to maintain a low cost of production and then the ability to rely on product differentiation versus a competitor.

According to Christiansen (2010), competitive advantage refers to any value that a business provides to motivate the customers for buying their product or service instead of their competitors' products and services, and create entry barriers for the potential and current opponents.

In recent decades, the concept of bank competition has been addressed and considered in several studies conducted throughout the world. Competition in the banking sector has attracted the attention of several local and international researchers.

A number of studies analyzing the competitiveness of European banks conducted in the early 2000s demonstrated a decline in the competition (Fernández de Guevara et $a l ., 2005)$. Several other studies reported that the bank integration process occurred extensively in the European Union in the years 2000-2010, through the simplification of capital transfer procedures, simple regulations in terms of operating licenses, removal of legal barriers to market entry, use of a common currency, and reduced risk of foreign exchange to the banks. All these accelerated the process of bank acquisition and expanding beyond borders, and provided cross-border services. Overall, the level of competition of the European banks increased over the past decade.

Repkova (2012) studied the competitiveness of the Czech banking system during the 2000-2010 period. In order to measure the level of competition, the author used the Lerner index, HHI index, and the CR index. Data were collected from $15 \mathrm{Czech}$ banks (which represented $90 \%$ of the market). In combination with general analysis, the author conducted a separate analysis of the credit market and the deposit market.

The results of the Lerner estimation demonstrated that the Czech banking market was not perfectly competitive and did not compete exclusively during the study period. The level of competition of the Czech banks decreased in the 2005-2010 period and was affected by the increase in capital costs. The Lerner analysis also revealed a low level of competition in the deposit market. The author also suggested that the extension of that study was to utilize the Panzar-Rosse model or the Bresnahan model to assess the competitiveness of the Czech banking system since these models are highly accurate.

Bolt and Humphrey (2012) studied the competitiveness in the US banks, using HHI, Lerner index, and H-statistics for measuring the level of competition. The authors argued that each of these indicators could be utilized to measure the competition, although in different ways. This was not a problem if all the three indicators exhibited a close correlation among the banks. However, the results of the study 
demonstrated that these three metrics may not correlate among the banks. In the present study, separate revenue data for traditional banking services (including consumer loans and business loans), along with securities trading activities, payment services, and investment banking services were analyzed.

Fungáčová et al. (2010) studied the market power of the Russian banks in the 20012007 period using the Lerner index. The results demonstrated that the level of competition among the Russian banks was slightly increased during the study period. The average Lerner rating of the Russian banks was as high as that of the banks in the developed countries, implying that the banking sector in Russia was not much competitive. Moreover, the study demonstrated no evidence of higher market power of the state-owned banks or lower market power of the foreign banks, which implied that market power did not depend on the type of ownership of the bank. In addition, the study identified the factors that influenced market power, including market concentration, risk factors, and non-linear influence of scale.

\section{Research Methodology}

\subsection{Research model}

In order to examine the factors affecting the level of competition in Vietnamese commercial banks, the studies conducted by Fungáčová et al. (2010) were followed in the present research. The research model used was as follows:

$$
\begin{aligned}
& \text { Lerner }_{i t}=\alpha+\beta_{1} \text { Lerner }_{i t-1}+\beta_{2} \text { EQTA }_{i t}+\beta_{3} \text { LOATA }_{i t}+\beta_{4} \text { ROE }_{i t}+\beta_{5} \text { CIR }_{i t}+\beta_{6} \\
& \text { BANKSIZE }_{i t}+\beta_{7} G D P_{i t}+\beta_{8} I N F_{i t}+u_{i t}
\end{aligned}
$$

The present study measured the level of competition of Vietnamese commercial banks by using the Lerner index. A number of competition indicators are available, although, in this study, the Lerner index originally developed by Lerner (1934) was used. This is a method used commonly in several studies conducted throughout the world. The Lerner index is defined as the difference between the output price and the marginal cost over the marginal cost, as represented by the formula:

$$
\text { Lerner }_{i t}=\frac{P_{i t}-M C_{i t}}{M C_{i t}}
$$

In particular, $\mathrm{P}$ is the price measured by Total Revenue per total assets of each bank and $\mathrm{MC}$ is the marginal cost of each bank. Without direct observation, MC is estimated on the basis of the total cost function. The Translog cost function was used as described below: 


$$
\begin{aligned}
& \operatorname{LnTC}=\alpha_{0}+\sum_{j=1}^{3} \alpha_{j} \times w_{i t}^{j}+\frac{1}{2} \sum_{j=1}^{3} \sum_{k=1}^{3} \alpha_{j k} \times \ln w_{i t}^{j} \times \ln w_{i t}^{k}+\beta_{1} \ln Y_{i t} \\
&+\frac{1}{2} \beta_{2}\left(\ln Y_{i t}\right)^{2}+\sum_{j=1}^{3} \beta_{j}^{\prime} \times \ln Y_{i t} \times \ln w_{i t}^{j}+\varphi_{1 t} \times T+\frac{1}{2} \varphi_{2 t} T^{2} \\
&+\sum_{j=1}^{3} \varphi_{3 t} \times T \times \ln w_{i t}^{j}+\varphi_{4 t} \times T \times \ln Y_{i t}+\mu_{t}+\varepsilon_{i t}
\end{aligned}
$$

where TC represents the total cost, w represents the price of the three inputs (personnel expenses/total assets, interest expenses/total deposits, and other operating expenses/fixed assets), $\mathrm{Y}$ represents the total assets, $\mathrm{T}$ represents the time trend reflecting the effect of technical progress, $\mu$ records the individual fixed effects, and $\varepsilon$ represents the error rate.

The total bank cost function was estimated using the fixed effects with a robust standard. Subsequent to estimating the total cost TC, the marginal cost was determined by using the first derivative of the total bank function, as described below:

$$
M C=(\operatorname{LnTC})^{I}=\frac{T C}{Y}\left(\beta_{1}+\beta_{2} \ln Y_{i t}+\sum_{j=1}^{3} \beta_{j}^{r} \times \ln w_{i t}^{j}+\varphi_{4 t} \times T\right)
$$

The large value obtained for the Lerner index (close to 1) implied that the weaker the competition among the banks, the stronger the level of competitiveness of each bank.

The previous models did not consider competition in the context of economic crisis. In this study, in order to evaluate the impact of these factors on the level of competition among Vietnamese commercial banks under normal conditions and under economic crisis, a CRISIS dummy variable was added to the model (1). The dummy variable value during the economic crisis of 2008-2009 was 1 , while 0 during the remaining years. The specific models were as follows:

Lerner $_{i t}=\alpha+\beta_{1}$ Lerner $_{i t-1}+\beta_{2}$ EQTA $_{i t}+\beta_{3}$ LOATA $_{i t}+\beta_{4}$ ROE $_{i t}+\beta_{5}$ CIR $_{i t}+\beta_{6}$ $B A N K S I Z E_{i t}+\beta_{7} G D P_{i t}+\beta_{8} I N F_{i t}+\beta_{9}$ CRISIS $_{t}+u_{i t}$

The variables in the model have been described in the following Table: 
Table 1. Variables in the research model:

\begin{tabular}{ll}
\hline Variables & Description \\
\hline Lerner & The level of competition, measured by the Lerner estimation results \\
LOATA & Capital structure, measured by the ratio of total equity to total assets \\
ROE & Loan to Total Assets ratio \\
CIR & Return on Equity \\
BANKSIZE & Cost Income ratio, measured by Total cost divided by Total revenue \\
GDP & Natural logarithm of total assets represented at Bank scale \\
INF & Chowth of the gross domestic product, measured by $\%$ GDP growth rate \\
CRISIS & $\begin{array}{l}\text { Represents a crisis condition. The value of the dummy variable is } 1 \\
\text { during the economic crisis of } 2008-2009 \text { and } 0 \text { for the remaining years }\end{array}$ \\
\hline
\end{tabular}

Source: Author's suggestion based on relevant studies.

\subsection{The Bayesian Multilevel Generalized Linear Model}

The Bayesian analysis commenced with the specification of a posterior model. The posterior model described the probability distribution of all model parameters on the basis of the observed data and certain prior knowledge. The posterior distribution had two components: a likelihood component, which included information regarding the model parameters based on the observed data, and a prior component, which included prior information (available prior to observing the data) regarding the model parameters. The likelihood and prior models were combined using the Bayes rule to produce the posterior distribution:

\section{Posterior $\propto$ Likelihood $\times$ Prior}

The posterior distribution was required to be estimated through simulations. MCMC sampling could be used to simulate the potentially extremely complex posterior models with an arbitrary level of precision. MCMC methods for simulating the Bayesian models are often demanding in terms of specifying an efficient sampling algorithm and verifying the convergence of the algorithm toward the desired posterior distribution. With Panel-data, the estimation was performed using the Bayesian multilevel generalized linear model.

$Y=\left\{y_{i j}\right\}$, where $\mathrm{i}=1, \ldots, \mathrm{m}$ and $\mathrm{j}=1, \ldots, \mathrm{n}_{\mathrm{i}}$. The multilevel generalized linear model could be expressed as follows:

$$
y_{i j}=\alpha_{i}+\beta_{i} X+\varepsilon_{i j}
$$


where $X=\left(x_{i j 1}, x_{i j 2}, \ldots, x_{i j p}\right)$ and $\alpha_{i}$ and $\beta_{i}$ represent individual-specific intercept and slope, $\varepsilon_{i j}$ represents errors.

The Likelihood function is defined as follows:

$$
\begin{aligned}
f\left(Y \mid \alpha_{i}, \beta_{i}, \delta^{2}, X\right) & =\prod_{i=1}^{m}\left[\prod_{j=1}^{n_{i}} \frac{1}{\sqrt{2 \pi \delta^{2}}} \exp \left\{-\frac{1}{2 \delta^{2}}\left(Y-\left(\alpha_{i}+\beta_{i} X\right)\right)^{2}\right\}\right] \\
& =\left(\frac{1}{\sqrt{2 \pi \delta^{2}}}\right)^{n} \exp \left(-\frac{1}{2 \delta^{2}} \sum_{i=1}^{m} \sum_{j=1}^{n_{i}}\left(Y-\left(\alpha_{i}+\beta_{i} X\right)\right)^{2}\right)
\end{aligned}
$$

In the present study, regression coefficients were assigned as independent normal priors with zero mean and variance of 10,000 . In the case of moderately-scaled regression coefficients, a variance of 10,000 should provide sufficient variation in the values of the coefficients so that the prior information exerts little impact on the results. The error variance was assigned inverse-gamma prior with shape and scale parameters of 0.01 .

\subsection{Research Data}

The present study included a sample of 24 commercial banks in Vietnam observed for the period between 2008 and 2016. This was a balanced panel, consisting of 216 observations. The data were derived from the annual financial statements of the commercial banks under observation. Information required for the research was collected from the audited financial statements, annual reports, and public disclosures of the commercial banks. The descriptive statistics for the variables used in the present study are presented in Table 2.

Table 2: Descriptive statistics of the sample

\begin{tabular}{lccccc}
\hline \multicolumn{1}{c}{ Variable } & \multicolumn{1}{c}{ Mean } & \multicolumn{1}{c}{ Std. Dev. } & \multicolumn{1}{c}{ Min } & \multicolumn{1}{c}{ Max } & \multicolumn{1}{c}{ Obs } \\
\hline BANKSIZE & 17.97906 & 1.256402 & 14.69872 & 20.72988 & 216 \\
EQTA & 0.1124928 & 0.0810996 & 0.0241392 & 0.999422 & 216 \\
LOANTA & 0.5113043 & 0.1564076 & 0.0046616 & 0.8516832 & 216 \\
CIR & 0.8932342 & 0.0794948 & 0.6137335 & 1.218747 & 216 \\
ROE & 0.084263 & 0.0866288 & -0.8200213 & 0.2846456 & 216 \\
GDP & 0.0591846 & 0.004797 & 0.0524737 & 0.0668 & 216 \\
INF & 0.090399 & 0.0692676 & 0.0063061 & 0.2311632 & 216
\end{tabular}




$\begin{array}{llllll}\text { LERNER } & .2957634 & .0849353 & .0214135 & .608538 & 216\end{array}$

Source: Calculated using package Stata 15.0.

Table 2 presents the statistics describing the variables used in the regression model of the factors affecting the level of competition of Vietnamese commercial banks. The data demonstrated heterogeneity among the banks in the sample. The bank scale variable BANKSIZE was calculated using the natural logarithm of the total assets, and had an average value of 17.98; the maximum value obtained for this variable (20.73) was that of BID in 2016, while the minimum value (14.70) was that of TIENPB in 2008. The ratio of equity to total assets (EQTA) exhibited an average value of $11.25 \%$; the maximum value (99.94\%) was that of TIENPB in 2008 when the bank was newly established and the entire asset was financed by equity, while the minimum value $(2.4 \%)$ was that of TienPB in 2016.

Loans to customers on total assets (LOANTA) reached a value of $51.13 \%$ on an average; the maximum value $(85.2 \%)$ was that of OCB in 2008 , while the minimum value $(0.46 \%)$ was that of TIENPB in 2008 when the bank was newly established. The operating expense on operating income ratio had a value of $89.32 \%$ on an average; the maximum value (121.87\%) was that of TIENPB in 2011, while the minimum value $(61.37 \%)$ was that of SGB in 2010 . The return on equity (ROE) averaged to $8.43 \%$, with the maximum value (28.5\%) obtained for ACB in 2008 and the minimum value $(-82 \%)$ obtained for TIENPB in 2011.

The variable representing the level of competition of Vietnam commercial banks was the LERNER index, with an average value of $29.58 \%$, a maximum value of $60.85 \%$ for TIENPB in 2008, and a minimum value of 2.14\% for TIENPB in 2011. In the case of macroeconomic environment measurements, the average economic growth rate for the nine years of the study period (2008-2016) was 5.92\%, with the minimum value of $5.25 \%$ in 2012 and the maximum value of $6.68 \% 2015$. The average inflation rate for the nine years from 2008 to 2016 was $9.04 \%$, the lowest rate was $0.63 \%$ in 2015 , and the highest rate was $23.12 \%$ in 2008 .

\section{Empirical Findings}

In order to consider the factors affecting the level of competition of Vietnamese commercial banks, Bayesian Multilevel Generalized Linear method was used. The estimated results were presented in Table 3.

MCMC methods used for simulating the Bayesian models are often demanding in terms of specifying an efficient sampling algorithm and verifying the convergence of the algorithm toward the desired posterior distribution. Therefore, the MCMC convergence was assessed in the present study. The convergence testing of the MCMCs was performed using trace plots. 
The study was commenced with trace plots, which are used to plot the values of the simulated parameters against the iteration number and connect the consecutive values using a line segment. In case of a well-mixing parameter, the range of the parameter is traversed rapidly by the MCMC chain, which caused the drawn lines to appear almost vertical and dense. Sparseness and trends in the trace plot of a parameter suggest convergence problems. The trace plots for the coefficients appeared almost vertical and dense, and exhibited no trend, demonstrating the convergence of MCMC.

Table 3: Estimated results of the model

\begin{tabular}{|c|c|c|c|c|c|c|}
\hline & Mean & Std. Dev. & MCSE & Median & $\begin{array}{l}\text { Equal-t } \\
\text { [95\% Cred. }\end{array}$ & $\begin{array}{l}\text { tailed } \\
\text { Interval] }\end{array}$ \\
\hline \multicolumn{7}{|l|}{ lerner } \\
\hline \multicolumn{7}{|l|}{ lerner } \\
\hline L1. & .0801164 & .0299777 & .00047 & .0803935 & .0217474 & .1399887 \\
\hline banksize & -.039283 & .004425 & .000285 & -.0391199 & -.0482323 & -.0307479 \\
\hline eqta & -.0143483 & .0614132 & .001342 & -.0137134 & -.1348301 & .1050609 \\
\hline loanta & -.0588648 & .0196558 & .000963 & -.05882 & -.0974647 & -.0202212 \\
\hline cir & -.8044939 & .0389674 & .000818 & -.8041698 & -.8806377 & -.7276592 \\
\hline roe & .046875 & .0286331 & .000457 & .0469108 & -.0091679 & .1027044 \\
\hline gdp & .1622568 & .3578893 & .011602 & .1681326 & -.5506725 & .8533717 \\
\hline inf & -.157294 & .0368688 & .000988 & -.1574645 & -.2292675 & -.0840511 \\
\hline crisis & .0021635 & .0057172 & .000148 & .0022314 & -.0090859 & .0132565 \\
\hline _cons & 1.725033 & .0880339 & .004628 & 1.723093 & 1.555111 & 1.902261 \\
\hline \multicolumn{7}{|l|}{ id } \\
\hline U0:sigma2 & .0016009 & .000542 & .000015 & .0014938 & .0008612 & .0029153 \\
\hline \multicolumn{7}{|l|}{ e.lerner } \\
\hline sigma 2 & .0003862 & .0000442 & $6.2 e-07$ & .0003835 & .0003101 & .0004811 \\
\hline
\end{tabular}

Note: For each parameter, we produced 12,500 MCMC estimates. MCMC estimates were simulated from a posterior distribution of the model parameters, after discarding the first 2,500 estimates for the burn-in period.

Source: Calculated results from Stata 15.0

Figure 1: Trace plots
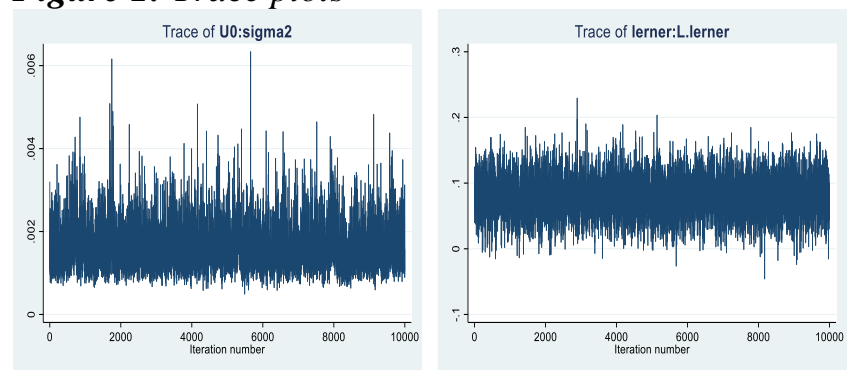

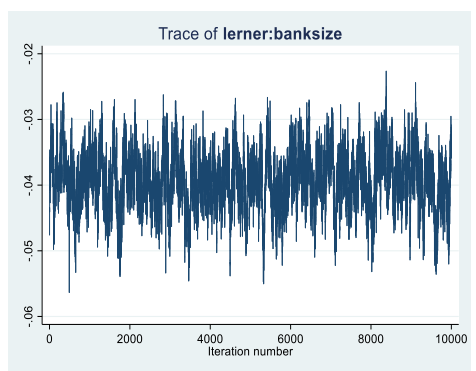



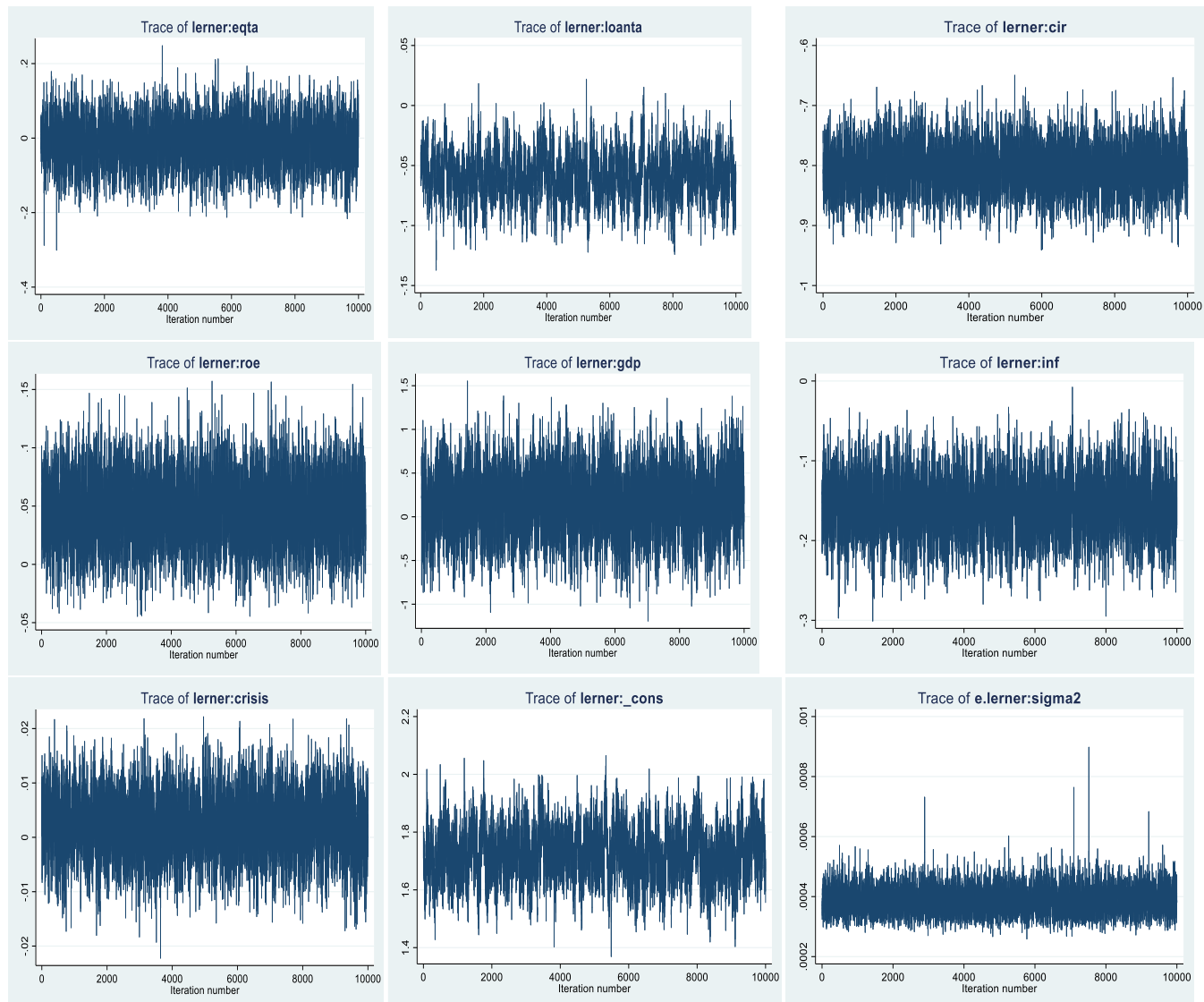

Source: Calculated results from Stata 15.0.

Table 3 presents the eight variables affecting the level of competition of Vietnamese commercial banks, including previous-year competition, equity on total assets ratio, loans on total assets ratio, operating expense on operating income ratio, return on equity, bank size, economic growth, and inflation rate, proposed in the model.

The posterior mean of the coefficient corresponding to the variable lerner $\mathrm{t}_{\mathrm{t}-1}$ was 0.08 , demonstrating that the level of competition of the bank is dependent on the level of competition in the previous year, which also demonstrated that the regression method used was suitable. The positive regression coefficient demonstrated a positive relationship of the Lerner index for this year with that of the previous year, which implied that if the Lerner index of the previous year is increased, that of this year will also increase, and vice versa. The higher the level of competition in the previous year, the higher the level of competition would be in the present year. Therefore, it could be stated that the regression method used was consistent with the dynamic table model. 
The posterior mean of the coefficient corresponding to the variable BANKSIZE was -0.039 , demonstrating a negative relationship between bank size and the Lerner index, which implied that as the bank size increased, the Lerner index decreased, and the level of competition among the banks increased. A high value for the total assets represents a large bank operation. With the bank's main activities being the mobilization of the deposits and loans, the bank total assets represented the ability to mobilize deposits from customers and big outstanding loans.

Expanding the business could increase competitive pressures. If total assets increase, but the quality of the assets is not high, bad debts would become high and it will be difficult to recover, which would result in the bank facing high credit risk, leading to liquidity risks, increase in banking costs, and increase in the competitive pressure of the commercial banks.

The posterior mean of the coefficient corresponding to the variable EQTA was -0.014 , demonstrating an inverse relationship of the equity to the total assets ratio with the Lerner index. When this ratio increased, the Lerner index decreased, and the level of competition of the commercial banks increased. EQTA is a variable that represents the financial capacity of commercial banks. The higher the ratio, the higher are the assets financed by equity.

Accordingly, the higher the financial autonomy of the banks, the higher the level of competition would be. In contrast, lower EQTA ratio represents that almost all of the bank assets are financed by external sources, such as mobilized capital, loans, and represent a lower level of competition. Therefore, it could be stated that the results of the present study were consistent with the economic theory, and provide further empirical evidence demonstrating that when banks have higher equity capital on total assets, the level of competition is higher.

The posterior mean of the coefficient corresponding to the variable LOANTA was -0.059 , demonstrating an inverse relationship between the loan to total asset ratio and the Lerner, implying that as the LOANTA ratio increased, the Lerner decreased, and the level of competition of the bank increased. When the outstanding loans increased, LOANTA increased. The income of the Vietnamese commercial banks is dependent mainly on the lending activities, so a high loan to total assets ratio could bring a high-income ratio and the competition level of the commercial banks could increase. It should be noted that the risk of competitive pressure could increase the risk of deteriorating credit quality, affecting the safe operation of banks.

The posterior mean of the coefficient corresponding to the variable CIR was -0.804 , demonstrating an inverse relationship between the ratio of costs to income ratio and the Lerner index. As the CIR ratio increases, the Lerner index reduces and the level of competition among banks increases. CIR represents the ability of commercial banks to manage business activities, as an increase in CIR reflects increased operating expenses or operating income. Operating expenses include labor costs, 
depreciation, etc., and the interest expenses and business expenses of the business services are deducted from the income. Therefore, the increase in the CIR implies that the costs for operations and administration is high for banks, and the corresponding decrease in the Lerner index implies an increase in the level of competition among the banks.

The posterior mean of the coefficient corresponding to the variable ROE was 0.047 , demonstrating a positive relationship between return on equity and the Lerner index, implying that when the ROE ratio increased, the Lerner index increased, and the level of competition among the banks decreased. ROE represents the profitability of commercial banks. Several studies have indicated that when the profitability increases, the competitive pressure of the commercial banks decreases.

This result might be due to the increase in bank profits which would add financial resources to the bank, assist in investing in technology, improve productivity, and reduce marginal costs, leading to an increase in the Lerner index, which in turn would reduce the competitive pressure among the commercial banks.

The posterior mean of the coefficient corresponding to the variable GDP was 0.162 , demonstrating a positive relationship between economic growth and the Lerner index, implying that as the economic growth rate increases, the Lerner index increases. At certain points in the economic cycle, higher economic growth leads to higher incomes and better education; this increases the demand for banking services.

The posterior mean of the coefficient corresponding to the variable INF was -0.157 , demonstrating an inverse relationship between inflation and the Lerner index, implying that as the inflation rate increased, the Lerner index decreased, and the level of bank competition increased, and vice versa. This result could be explained by the increase in the inflation leading to an increase in the operating expenses of the bank, which in turn would lead to increased competition among the commercial banks.

In particular, during the 2008-2009 crisis, the results demonstrated that the posterior mean of the coefficient corresponding to the variable CRISIS was 0.002, indicating a positive relationship between the crisis and the Lerner index. The level of bank competition in crisis was low. During an economic crisis, customers become more cautious regarding borrowing and dealing with the banks. In addition, banks in crisis require prioritizing all the resources to maintain operations and overcome the crisis. After a period of crisis, competitive pressure among the banks will probably increase again.

\section{Conclusion and Policy Implication}

The results indicate that as the LOANTA ratio increased, the Lerner decreased, and the level of competition of the bank increased. However, It should be noted that the 
risk of competitive pressure could increase the risk of deteriorating credit quality, affecting the safe operation of banks. Therefore, it is necessary for the banks to strictly control their credit activities and undertake measures to actively deal with bad debts, debts recovered from customers or the debt sold in order to increase the quality of loan assets, and optimize the performance to enhance the bank competitiveness.

In addition, when the ROE ratio increased, the Lerner index increased, and the level of competition among the banks decreased. So, the Vietnamese commercial banks need to diversify their income sources. the banks should increase the level of equity, invest, and develop modern technology for effective operations of the system. Modern technology is a precondition for the deployment of novel services, and for quick and complete information updates on minimizing risks.

On the other hand, modern technology also assists the banks in reducing costs and transaction time, while ensuring the safety of the customers, thereby providing efficient protection to customers. The commercial banks require exchanging and cooperating in order to learn the experience of foreign banks worldwide. Banks should be linked with service providers in order to develop a wide range of products based on modern science and technology. Moreover, it is necessary to invest in modern machinery and good security, and at the same time, develop a strict management and supervision mechanism, in order to provide quick and satisfactory handling of the customers.

The results also indicate that the macro factors such as GDP, INF affect the level of competition of the bank. So, the Vietnamese commercial banks need to control these factors well. However, the macro variables of commercial banks are often out of control. Therefore, it is necessary to actively deal with the changes in the macroeconomy in order to preserve the bank's assets. This would assist the banks in coping with economic shocks and in predicting risk so that the banks could provide a suitable strategy and ensure profitability while preserving the assets of the bank.

Besides, banks should develop and provide diversified products to be consistent with customer demand. Banks should conduct market research and study customer segmentation in order to offer suitable products to different customers, and formulate preferential policies on the interest rates and promotions that are suitable for each customer segmentation.

\section{References:}

Bolt, W., Humphrey, D. 2012. A Frontier Measure of U.S. Banking Competition. De Nederlandsche Bank Working Paper No. 359. Available at SSRN: https://ssrn.com/abstract=2187300.

Christiansen, A. 2010. Der "More Economic Approach" in Der EU-Fusionskontrolle: Entwicklung, Konzeptionelle Grundlagen Und Kritische Analyse. Lang. 
https://books.google.com.vn/books?id=n5ZE8X1kwMEC.

Fernández de Guevara, J., Maudos, J., Perez, F. 2005. Market Power in European Banking

Sectors. Journal of Financial Services Research, 27, 109-137.

Fungáčová, Z., Laura, S., Laurent, W. 2010. Market Power in the Russian Banking Industry.

International Economics, 124, 127-145.

http://www.sciencedirect.com/science/article/pii/S2110701713600220.

Lerner, A.P. 1934. The Concept of Monopoly and the Measurement of Monopoly Power.

The Review of Economic Studies, 1(3), 157-175. https://doi.org/10.2307\%2F2967480.

Porter, M.E. 1985. Competitive Advantage Creating and Sustaining Superior Performance.

New York, FreePress, 580.

Repkova, I. 2012. Market Power in the Czech Banking Sector. Journal of Competitiveness,

4(1), 143-155. http://www.cjournal.cz/index.php?hid=clanek\&cid=91.

Samuelson, P.A., Nordhaus, W.D. 1985. Economics, 12th ed. New York, McGraw-Hill. 
